\title{
Capilaroscopia en las Enfermedades del Tejido Conectivo (ETC)
}

\section{Luis J. Catoggio}

Médico de Planta y ExJefe, Sección Reumatología. Hospital Italiano de Buenos Aires.

Profesor Asociado de Medicina, Instituto Universitario Escuela de Medicina Hospital Italiano de Buenos Aires.

Director Asociado, Carrera de Especialistas en Reumatología, Facultad de Medicina, UBA.

Podríamos decir que la capilaroscopia en nuestra especialidad fue puesta en el tapete por Hildegard Maricq allá por la década del 70, trabajando en el grupo de E. Carwile Leroy ${ }^{1}$.

La frecuencia del fenómeno de Raynaud en ciertos climas y la dificultad de diferenciar al Raynaud primario del secundario era un tema recurrente, particularmente en pacientes pasibles de desarrollar alguna ETC, particularmente la esclerosis sistémica.

La capilaroscopia parecía ofrecer una herramienta útil en este sentido y en nuestro país fue rápidamente adoptada especialmente por el grupo del Hospital Rivadavia, dirigido por la Dra. Coti Fonseca, formadora de la mayoría de los que luego adoptaron la técnica ${ }^{2}$. La limitante era el costo del aparato, por un lado, y la adquisición de la experiencia, por el otro. Trabajos de aquella época demostraban que uno podía tener una adecuada apreciación usando un oftalmoscopio ${ }^{3}$, pero esta práctica no se difundió por lo menos en nuestro medio.

Por la misma época aparecieron autoanticuerpos cuya identificación también permitían suponer, en una paciente con fenómeno de Raynaud, si éste era primario o parte de un espectro relacionado con una ETC ${ }^{4}$.

Sin embargo, para esto se necesitaba un microscopio de inmunofluorescencia, no fácilmente accesible en muchos lugares, y en cuanto a otros anticuerpos, la experiencia, el acceso a kits adecuados, etc. Esto hizo durante años que estos no fuesen tan accesibles a los servicios de Reumatología de nuestro medio.

A medida que se hacía todo más accesible, fueron progresando en forma digamos, paralela, la serología y la capilaroscopia como "predictores" de posible ETC asociada al fenómeno de Raynaud (además, por supuesto, de todo lo que podía significar en el conocimiento de la fisiología vascular capilar no relacionada necesariamente con nuestra especialidad).

Hoy día, los "microscopios" manuales son ya más accesibles, muchos médicos jóvenes y no tanto se han hecho prácticos en el análisis de la capilaroscopia, se pueden almacenar satisfactoriamente las imágenes con medios digitales y podríamos decir que en muchos lugares de nuestro país, ésta se ha hecho un arma auxiliar frecuente frente al paciente con fenómeno de Raynaud.

Hoy, a casi cualquier paciente con fenómeno de Raynaud, además de una prolija historia y examen físico, se le puede ofrecer una capilaroscopia y un perfil básico de anticuerpos.

Con estos resultados, uno puede asegurar con bastante certeza la ausencia de una ETC asociada en caso de ausencia de anticuerpos y capilo normal o, por el contrario, una vigilancia más estrecha y posibles estudios siempre relacionados con la clínica del/la paciente, en caso de detectar anormalidades ${ }^{5}$.
Su valor como predictor de aparición de úlceras, variaciones con distintos tratamientos para el Raynaud, y otros, permanecen aún con cierto grado de conflicto pero ofreciendo datos útiles y probablemente más limitados a grupos con mayor experiencia que aquellos que usamos la capilaroscopia como elemento de rastreo ${ }^{6-8}$.

En este número, se presenta un trabajo explicando los patrones más clásicos de capilaroscopia y su uso en el diagnóstico temprano de la Esclerosis Sistémica.

\section{Bibliografía}

1. Maricq HR, LeRoy EC. Patterns of finger capillary abnormalities in connective tissue diseases by "Widefield" microscopy. Arthritis Rheum 1973; 1:195-205.

2. Fonseca, Maria L Sormani de. Capilaroscopia - Editorial Producere Mc Dowell S.A.- Buenos Aires, 2000.

3. Anders HJ, Sigl T, Schattenkirchner M. Differentiation between primary and secondary Raynaud's phenomenon: a prospective study comparing nailfold capillaroscopy using an ophthalmoscope or stereomicroscope Ann Rheum Dis 2001; 60:407-409.

4. Kallenberg CG, Pastoor GW, Wouda AA, The TH. Antinuclear antibodies in patients with Raynaud's phenomenon; clinical significance of anticentromere antibodies. Ann Rheum Dis. 1982, 41:382-87.

5. Ingegnoli F, Boracchi $P$, Gualtierotti R, Lubatti C, Meani L, Zahalkova L, Zeni S, and Fantini F. Prognostic Model Based on Nailfold Capillaroscopy for Identifying Raynaud's Phenomenon Patients at High Risk for the Development of a Scleroderma Spectrum Disorder Arthritis Rheum 2008; 58, 7:2174-2182.

6. Sebastiani M. Manfredi A, Colaci M, D’Amikco R, Malagoldi V, Giuggioli D, Ferri C. Capillaroscopic Skin Ulcer Risk Index: A New Prognostic Tool for Digital Skin Ulcer Development in Systemic Sclerosis Patients Arthritis Rheum (Arthritis Care \& Research) 2009; 61, 5:688-694.

7. Valentini G, Cuomo G, Abignano G. Early Systemic sclerosis: assessment of clinical and pre-clinical organ involvement in patients with different disease features. Rheumatology 2011; 50:317-323.

8. Smith V, Decuman S, Sulli A, Bonroy C, Piettte Y, Deschepper E, de Keyser F, Cutolo M. Do worsening scleroderma capillaroscopic patterns predict future severe organ involvement? a pilot study. Ann Rheum Dis. 2012; 10:1636-9. 